\title{
Seismic structure of the subducting seamounts on the trench axis: Erimo Seamount and Daiichi-Kashima Seamount, northern and southern ends of the Japan Trench
}

\author{
Azusa Nishizawa, Kentaro Kaneda, Naoko Watanabe, and Mitsuhiro Oikawa \\ Hydrographic and Oceanographic Department, Japan Coast Guard, Tokyo 104-0045, Japan \\ (Received September 30, 2008; Revised January 23, 2009; Accepted January 26, 2009; Online published February 23, 2009)
}

\begin{abstract}
We present detailed $P$-wave velocity models of subducting seamounts from two wide-angle seismic experiments across the Erimo Seamount and Daiichi-Kashima Seamount, northern and southern ends of the Japan Trench. Common characteristics of the velocity models of the seamounts are that the maximum crustal thicknesses of the seamounts are $12-17 \mathrm{~km}$ thicker than a typical oceanic crust and that $P_{\mathrm{n}}$ velocities beneath the seamounts are approximately $7.7 \mathrm{~km} / \mathrm{s}$, i.e., slower then those of the neighboring area. These features are very similar to the crustal models for the seamounts produced by the Cretaceous off-ridge volcanism on the Pacific Basin.
\end{abstract}

Key words: Erimo Seamount, Daiichi-Kashima Seamount, seamount subduction, seismic structure, ocean bottom seismograph.

\section{Introduction}

The subducted seamount in seismogenic zones plays a crucial role in the earthquake rupture process. For example, Kodaira et al. (2002) showed a clear image of a subducting seamount beneath the Nankai Trough that worked as a barrier of the rupture of the 1946 Nankai Earthquake. Alternatively, Husen et al. (2002) interpreted a subducted seamount as an asperity whose rupture caused the 1990 Gulf of Nicoya earthquake $\left(M_{\mathrm{w}} 7.0\right)$ in Costa Rica. Active seismicity between the upper and lower seismic planes of the double seismic zone in the subducting plate is supposed to be related to the subducted seamount in the southern part of Tohoku district, Japan (Suganomata et al., 2006). Therefore, detailed seismic structure of a subducting seamount provides significant information of earthquake occurrences.

The Pacific plate is moving towards the west-northwest (WNW) at a rate of approximately $8 \mathrm{~cm} /$ year east of the Japan arc and is subducting at the Japan Trench where seamount subduction is considered to occur around its north and south ends (Fig. 1). The Erimo Seamount (ERS) is positioned at the northern tip of the Japan Trench. The shallowest water depth of ERS is approximately 3,700 m and the difference in elevation from the ambient seafloor is approximately 4,200 m. The Takuyo-Daiichi Seamount and Ryofu-Daini Seamount are distributed around this region on the Pacific plate. In the southern end of the trench, the Daiichi-Kashima Seamount (DKS), one of the Joban Seamount Chain, is split into two bodies with a vertical offset of more than $1 \mathrm{~km}$, subducting off Choshi. The summit depth is approximately $3,500 \mathrm{~m}$ and the relative elevation is

Copy right(c) The Society of Geomagnetism and Earth, Planetary and Space Sciences (SGEPSS); The Seismological Society of Japan; The Volcanological Society of Japan; The Geodetic Society of Japan; The Japanese Society for Planetary Sciences; TERRAPUB
3,000-4,000 m. Many seamounts exist on the Pacific plate and will sequentially subduct following DKS. Both the ERS and DKS have been dated at 100-120 Ma (Takigami et al., 1989) and are considered to be produced by Cretaceous offridge volcanism.

We conducted seismic reflection and wide-angle seismic experiments to elucidate precise crust and uppermost mantle $P$-wave velocity structure of the subducting seamounts and to provide information on the physical properties of possible seismic asperities and barriers at the seismogenic zone.

\section{Data Acquisition and Modeling}

Two seismic surveys were carried out in the fall of 2006: (1) the profile ERr1, traverses ERS at the junction of the Kurile Trench and Japan Trench (Fig. 1); (2) the profile DKr1 cuts across the DKS at the southern end of the Japan Trench. The profile lengths are $150 \mathrm{~km}$ for ERr1 and $160 \mathrm{~km}$ for DKr1, respectively. We used a non-tuned array of four airguns with a total volume of $6000 \mathrm{inch}^{3}$ (98 1) as a controlled seismic source for the wide-angle seismic survey. The airgun array provided by $S / V$ Shoyo was fired approximately every $200 \mathrm{~m}$. We deployed 30 ocean bottom seismographs (OBS) with a $5-\mathrm{km}$ receiver spacing for each line. Every OBS instrument is equipped with a threecomponent $4.5-\mathrm{Hz}$ geophone and a hydrophone. However, the hydrophone sensor was dismounted for stations with water depths $>6,500 \mathrm{~m}$ due to its pressure limit.

The outputs from each sensor were continuously recorded on a hard disc at a sampling rate of $200 \mathrm{~Hz}$ with a resolution of 24 bits. Shot and OBS locations were obtained from the ship's GPS navigation system, and each OBS was relocated using the direct water wave arrivals it recorded (Oshida et al., 2008). We also acquired multi-channel (240 


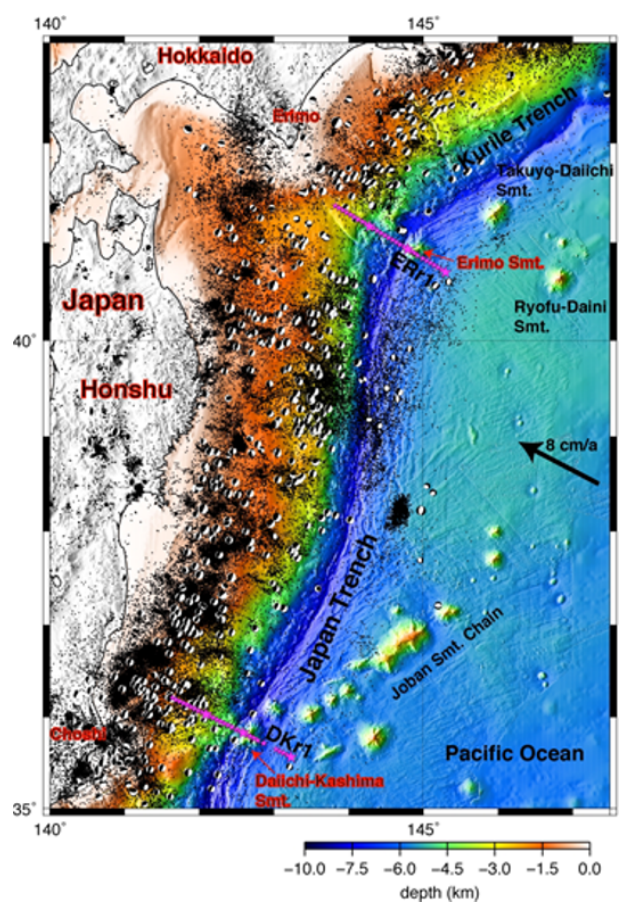

Fig. 1. Position of two seismic profiles across the Japan Trench. Pink asterisks show the position of the OBSs. Dots are epicenters with $M \geq 2$ and depth $\leq 50 \mathrm{~km}$ during July $1926-2008$ as determined by the Japan Meteorological Agency. Focal mechanisms of the earthquakes shallower than $50 \mathrm{~km}$ during July 1976-2008 are from the Harvard centroid-moment tensor (CMT) catalog. Seafloor topography is based on multi-beam swath bathymetric data.

channels with 3,460-m long streamer) seismic (MCS) reflection data for same profile where the airgun array with a capacity of 3,000 $\mathrm{inch}^{3}$ (49 1) was shot at a 50-m distance.

The procedures adopted for data processing and velocity analysis in this study are the same as those of Nishizawa et al. (2007) and Kasahara et al. (2007). Initially, the top-most sediment structure is modeled using MCS data. $P$-wave velocity models are then constructed by a tomographic inversion (tomo2d: Korenaga et al., 2000) and forward modeling using a two-dimensional raytracing algorithm (Fujie et al., 2000; Kubota et al., 2005). In addition to the travel time data, we also modeled the amplitude data by calculating two-dimensional (2-D) synthetic seismograms using a finite difference method, E3D (Larsen and Schultz, 1995).

\section{Results}

\subsection{Erimo Seamount}

Figure 2(a) shows the $P$-wave velocity model for profile ERr1. In the first tomographic inversion, we used only clear first-arrival time data as the velocity model deeper than $15 \mathrm{~km}$ was not well resolved in the checkerboard test result. We then conducted forward modeling using $P_{\mathrm{m}} P$ and faint $P_{\mathrm{n}}$ arrivals at far offsets to estimate the deeper region. The final model was examined by tomographic inversion again, and the root-mean-square (RMS) misfit between the observed and calculated first arrivals for the model was $28 \mathrm{~ms}$. The misfits in the forward modeling also using $P_{\mathrm{m}} P$ and vague arrivals were at a maximum of $0.2 \mathrm{~s}$ (e.g., Fig. 3).

An example of the travel time fitting is shown in the top

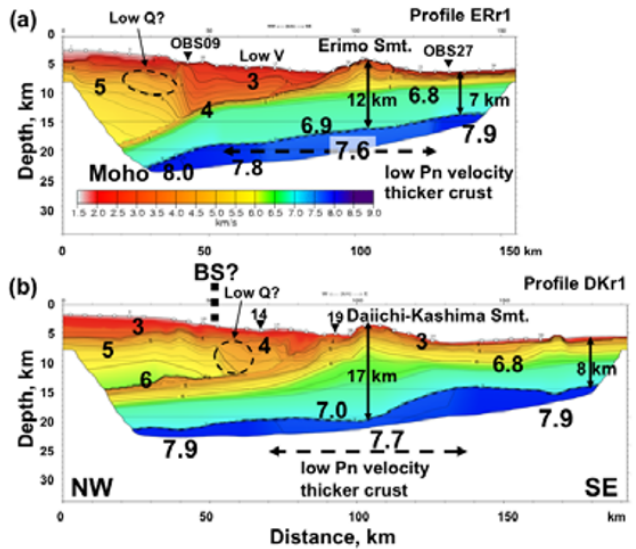

Fig. 2. $P$-wave velocity models across the Erimo Seamount (a) and Daiichi-Kashima Seamount (b) derived from tomographic inversion and forward modeling using two-dimensional ray tracing. Iso-velocity contours with an interval of $0.25 \mathrm{~km} / \mathrm{s}$ are shown. Dashed ellipsoids and vertical dashed line indicate the estimated position of low- $Q$ zones and backstop, respectively. The plate boundary beneath the landward of the trench axis along the profile $\mathrm{DKr} 1$ is not determined definitely compared with that of ERr1.
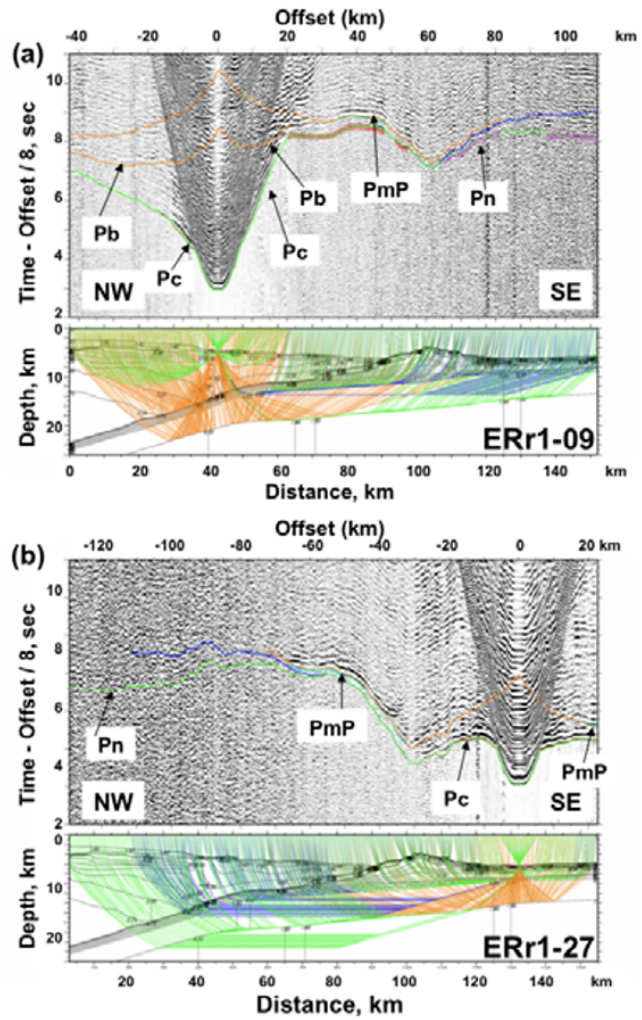

Fig. 3. (a) Vertical geophone record section (top) and ray diagram (bottom) for OBS09, profile ERr1. The position of the OBSs is shown by inverted triangles in Fig. 2. A gain factor proportional to distance has been used to enhance the distant seismograms. The reduction velocity is $8 \mathrm{~km} / \mathrm{s}$. Picked arrival times with error for first and later arrivals (vertical bars) and calculated travel time curves of first arrivals, $P_{\mathrm{m}} P$, and reflection at the plate boundary for the model are superimposed. (b) Same as (a) but for OBS27.

of Fig. 3(a) for OBS09. The recorded section shows different apparent velocities of refraction arrivals from the upper crust $\left(P_{\mathrm{c}}\right)$ between the NW and SE sides of OBS09. The thickness of material with $V_{p}<4 \mathrm{~km} / \mathrm{s}$ approaches approx- 


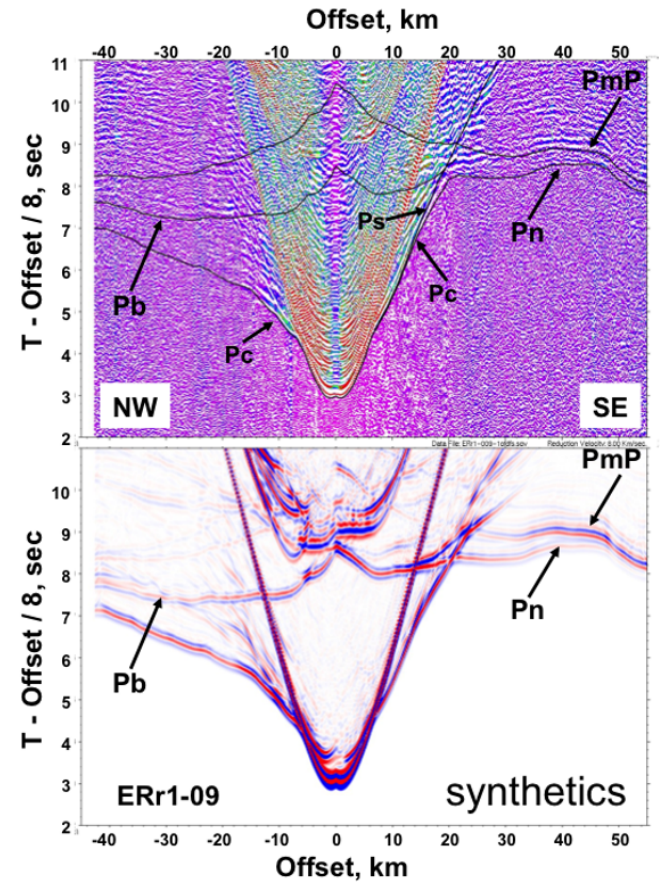

Fig. 4. Comparison of observed record section (top) and synthetic seismogram (bottom) for OBS09, profile ERr1. The calculated travel time curves for refraction arrivals from the sediment $\left(P_{\mathrm{s}}\right)$, crust $\left(P_{\mathrm{c}}\right)$ and uppermost mantle $\left(P_{\mathrm{n}}\right)$, and reflection arrivals from the top of the plate boundary $\left(P_{\mathrm{b}}\right)$ and from Moho of the subducting plate $\left(P_{\mathrm{m}} P\right)$ are superimposed on the observed record section. The reflections from the plate boundary $\left(P_{\mathrm{b}}\right)$ in the NW side and $P_{\mathrm{m}} P$ in the SE side in the observed data are well reproduced in the synthetics.

imately $9 \mathrm{~km}$ in the SE area. In contrast, the $V_{p}>4 \mathrm{~km} / \mathrm{s}$ materials are ascending to approximately $5 \mathrm{~km}$ below the seafloor in the NW region. Amplitudes of the first arrivals with NW offsets of more than $20 \mathrm{~km}$ are very small and disappear. The recorded sections of OBS01-10 show the same feature, which suggests low- $Q$ or low-velocity materials exist in the area at $20-40 \mathrm{~km}$ from the NW end and deeper than $6 \mathrm{~km}$ (dashed ellipse in Fig. 2). For example, synthetic seismograms calculated for the velocity model with a constant $Q$ crust cannot explain the observed record section (Fig. 4).

The thickness of the ERS crust was derived from clear $P_{\mathrm{m}} P$ arrivals within an error of $0.2 \mathrm{~s}$ by forward modeling (Fig. 3). The maximum thickness is approximately $12 \mathrm{~km}$ and thicker than that of the oceanic crust of $7 \mathrm{~km}$ to the east (Fig. 2). The region with a rather thick lower crust and low $P_{\mathrm{n}}$ velocity of $7.6-7.8 \mathrm{~km} / \mathrm{s}$ shown by a horizontal dashed line in Fig. 2(a) extends unevenly landward from the peak of the ERS, which provides some evidence that there might have been another seamount subducted in the past.

\subsection{Daiichi-Kashima Seamount}

The $P$-wave velocity model for profile $\mathrm{DKr} 1$ is presented in Fig. 2(b). The model within approximately $5 \mathrm{~km}$ below the seafloor was derived from the tomographic inversion using clear first arrivals. We estimated the deeper structures by forward modeling with reflection and distant refraction signals. Figure 5 shows the calculated travel times on the observed recorded sections and ray diagrams for OBS014 and OBS019. The Moho reflections from the subducting
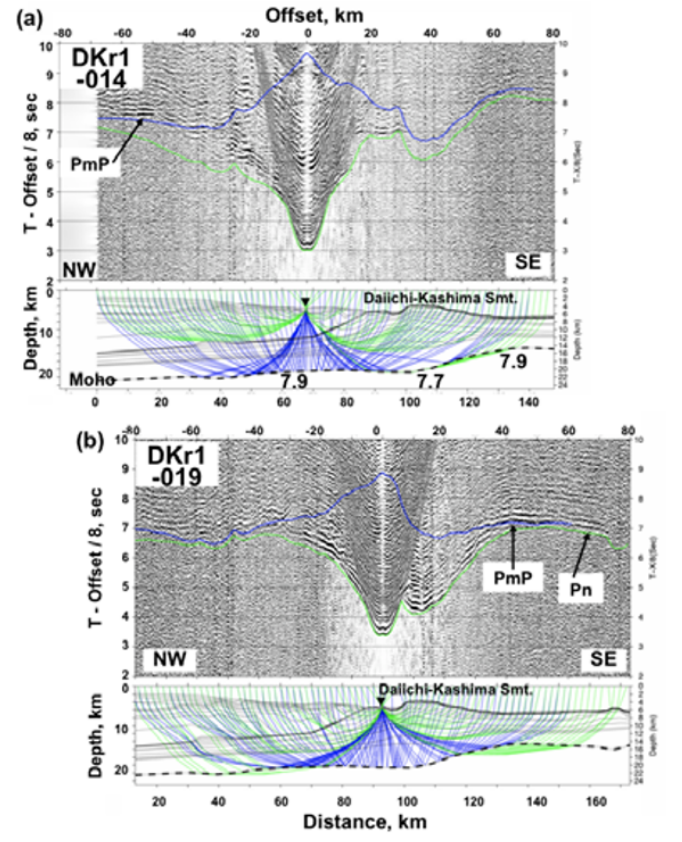

Fig. 5. (a) Vertical geophone record section and ray diagram for OBS14, profile DKr1. Green and blue curves on the record section are calculated first arrivals and $P_{\mathrm{m}} P$ travel times for the model, respectively. The positions of the OBSs are shown by inverted triangles in Fig. 2. (b) Same as (a) but for OBS19.

plate are clearly identified. The fitting of $P_{\mathrm{n}}$ and $P_{\mathrm{m}} P$ between the observed and calculated travel times can constrain lateral variation in Moho depths and $P_{\mathrm{n}}$ velocities. The final inversion using first arrival data at far offsets resulted in an RMS misfit of $35 \mathrm{~ms}$, and the misfits in the forward modeling, including $P_{\mathrm{m}} P$ data, were within $0.2 \mathrm{~s}$. The maximum crustal thickness of DKS is approximately $17 \mathrm{~km}$ beneath the region where the seamount splits between east and west. The DKS crust is significantly thicker than the ambient oceanic crust and $P_{\mathrm{n}}$ velocity beneath DKS is lower, $7.7 \mathrm{~km} / \mathrm{s}$.

A small swell exists on the plate boundary at a distance of $30-40 \mathrm{~km}$ from the NW end, and its crust is rather thicker in this region. Although the travel time differences due to the presence or absence of the swell is comparable to the travel time fitting error of $0.1 \mathrm{~s}$ in the forward modeling, the swell model reveals a better fit than the model without swell. Similarly, a swell at the line distance of $170 \mathrm{~km}$ is preferable. While the first swell is at the plate boundary, the $170-\mathrm{km}$ swell is on the Pacific plate.

First arrivals at the NW offsets $>20 \mathrm{~km}$ in the OBS014 recorded section are invisible in Fig. 5(a). Several OBS records also suggest that an attenuation zone exists in a dashed ellipse area beneath the landward slope (Fig. 2(b)).

\section{Discussion}

We obtained the $P$ velocity models related to Erimo and Daiichi-Kashima Seamount subduction at both ends of the Japan Trench. The common characteristics between these are thicker crusts and lower $P_{\mathrm{n}}$ velocities under the seamounts relative to those of the ambient regions. The maximum crustal thicknesses of ERS and DKS are 12 and $17 \mathrm{~km}$, respectively, and the widths of the thicker crusts are 
50-60 km. Features of a subducted seamount similar to those obtained in our study were revealed beneath the landward slope of the Nankai Trough by Kodaira et al. (2002). The dimension of the buried seamount at a $10-\mathrm{km}$ depth was estimated to be $13 \mathrm{~km}$ thick by $50 \mathrm{~km}$ wide, which is comparable to our results. A low $P_{\mathrm{n}}$ velocity of $7.5 \mathrm{~km} / \mathrm{s}$ has also been detected under the subducted seamount (Kodaira et al., 2002), suggesting that the low $V_{p}$ is due to serpentinized mantle associated with the past plume activity.

Numerous seamounts formed by active volcanism during the Cretaceous are distributed on the western Pacific Basin. Extensive surveys have recently been conducted to elucidate the fine velocity structures of typical oceanic crusts and seamounts (e.g. Kaneda et al., 2007a, b). $P$-wave velocity models obtained for several seamounts in the MarcusWake Seamount Group showed that most seamounts have a thicker crust $>8 \mathrm{~km}$, higher $V_{p}=\sim 7.2 \mathrm{~km} / \mathrm{s}$ at the bottom of the lower crusts, and slower $P_{\mathrm{n}}<7.8 \mathrm{~km} / \mathrm{s}$, with few exceptions (Kaneda et al., 2007a, b). Although the lower crustal velocities were not well determined due to a lack of ray coverage in our ERS and DKS models, the thicker crusts and lower $P_{\mathrm{n}}$ velocities beneath ERS and DKS compared to a typical oceanic model show similar characteristics to the Cretaceous seamounts on the Pacific plate.

The thick crust and low $P_{\mathrm{n}}$ region extends disproportionately landward from the peak of ERS, which indicates that a previously subducted seamount exists northwestward of ERS, as suggested by Yamazaki and Okamura (1989). On the other hand, Mochizuki et al. (2008) found a subducted seamount on the plate boundary beneath the landward slope off Choshi by OBS observations near profile DKr1. Their seamount location corresponds to the small swell imaged at distances 30-40 km in Fig. 2(b). Mochizuki et al. (2008) interpreted the data to indicate that the seamount had subducted before DKS subduction and that it is located at the edge of the 1982 event (M 7.0) rupture zone. They also suggested that the interplate coupling was weak over the seamount based on the results of the observed seismicity and rupture propagation of the 1982 event.

In addition to the seamount structures, we detected a backstop structure where updip limit of the seismogenic zone along the subducting plate boundary coincides to the higher velocity of island arc crust beneath the landward slope to the west of the DKS (Figs. 1, 2). Such a relationship is not clear at the ERS region because of low seismicity. However, Obara et al. (2004) detected low-frequency events occurring on the plate boundary as a dynamic process of the tectonic erosion by the subducted seamount.

Information on the positions and nature of asperities on a plate boundary is essential to understanding subduction earthquakes. It is very crucial to have detailed knowledge on the velocity structures of subducting seamounts since the seamount is one of the possible candidates of a barrier and/or asperity of large earthquakes. Our aim was to construct structural models that will contribute to the estimation of frictional parameters along a fault plane and to available input data for large earthquake simulations.

Acknowledgments. The authors gratefully acknowledge Prof. emeritus J. Kasahara, the members of Continental Shelf Surveys Co. Ltd., Mr. Nakajima, JGI Inc. and Mr. Yano, KGE Co., Ltd. for data processing and analyses. The Captain and crew of $S / V$ Shoyo and S/V Takuyo, Japan Coast Guard are acknowledged. The members of the Hydrographic and Oceanographic Department, JCG, are thanked for their management of the seismic surveys. Comments of the reviewers, Drs. K. Mochizuki and W. R. Jacoby helped considerably to improve the manuscript. Most of the figures in this paper were made using the GMT graphic package of Wessel and Smith (1998).

\section{References}

Fujie, G., J. Kasahara, T. Sato, and K. Mochizuki, Traveltime and raypath computation: A new method in a heterogeneous medium, J. Soc. Explor. Geophys. Jpn., 53, 1-11, 2000.

Husen, S., E. Kissling, and R. Quintero, Tomographic evidence for a subducting seamount beneath the Gulf of Nicoya, Costa Rica: The cause of the $1990 \mathrm{Mw}=7.0$ Gulf of Nicoya earthquake, Geophys. Res. Lett., 29, 10.1029/2001GL014045, 2002.

Kaneda, K., S. Kodaira, N. Takahashi, and A. Nishizawa, Velocity structure model of Marcus-Wake seamounts group: seamount formation on the oceanic seafloor, Abstr. Seismol. Soc. Jpn., C32-02, 2007a.

Kaneda, K., A. Nishizawa, A. Kamimura, and J. Kasahara, Seismic velocity structure model of seamounts around Minami-Tori Shima: a structural variation of uppermost mantle beneath seamounts, Abstr. Seismol. Soc. Jpn., 2007b.

Kasahara, J. et al., A new integrated method for the crustal structure analysis using OBSs and control sources, Eos Trans. AGU, 88(52), Fall Meet. Suppl., Abstract S12A-06, 2007.

Kodaira, S., E. Kurashimo, J.-O. Park, N. Takahashi, A. Nakanishi, S. Miura, T. Iwasaki, N. Hirata, K. Ito, and Y. Kaneda, Structural factors controlling the rupture process of a megathrust earthquake at the Nankai trough seismogenic zone, Geophys. J. Int., 149, 815-835, 2002.

Korenaga, J., W. S. Holbrook, G. M. Kent, P. B. Kelemen, R. S. Detrick, H.-C. Larsen, J. R. Hopper, and T. Dahl-Jensen, Crustal structure of the southeast Greenland margin from joint refraction and reflection seismic tomography, J. Geophys. Res., 105, 21591-21614, 10.1029/2000JB900188, 2000

Kubota, R., E. Nishiyama, K. Murase, and J. Kasahara, Fast computation algorithm of ray-paths and their travel times including later arrivals for a multi-layered earth model, Eos Trans. AGU, 86(52), Fall Meet. Suppl., Abstract S41A-0966, 2005.

Larsen, S. C. and C. A. Schultz, ELAS3D: 2D/3D elastic finite-difference wave propagation code, LLNL internal report, 18 p., 1995.

Mochizuki, K., T. Yamada, M. Shinohara, Y. Yamanaka, and T. Kanazawa, Weal inerplate coupling by seamounts and repeating $M \sim 7$ earthquakes, Science, 321, 1194-1197, 2008.

Nishizawa, A., K. Kaneda, Y. Katagiri, and J. Kasahara, Variation in crustal structure along the Kyushu-Palau Ridge at $15-21^{\circ} \mathrm{N}$ on the Philippine Sea plate based on seismic refraction profiles, Earth Planets Space, 59, e17-e20, 2007.

Obara, K., Y. Haryu, Y. Ito, and K. Shiomi, Low frequency events occurred during the sequence of aftershock activity of the 2003 Tokachi-Oki earthquake; a dynamic process of the tectonic erosion by subducted seamount, Earth Planets Space, 56, 347-351, 2004.

Oshida, A., R. Kubota, E. Nishiyama, J. Ando, J. Kasahara, A. Nishizawa, and K. Kaneda, A new method for determining OBS positions for crustal structure studies, using airgun shots and precise bathymetric data, Explor. Geophys., 39, 15-25, 2008; Butsuri-Tansa, 61, 15-25, 2008; Mulli-Tamsa, 11, 15-25, 2008.

Suganomata, J., T. Okada, A. Hasegawa, K. Sakoda, and S. H. Kirby, Relocation of intermediate-depth earthquakes beneath the NE Japan arc by double-difference location method, Zisin (J. Seismol. Soc. Jpn.), 59 1-18, 2006.

Takigami, Y., I. Kaneoka, T. Ishii, and Y. Nakamura, 40Ar-39Ar ages of igneous rocks recovered from Daiichi-Kashima and Erimo Seamounts during the KAIKO Project, Palaeo-geograp. Palaeoclimatol. Palaeoeco., 71, 71-81, 1989.

Wessel, P. and W. H. F. Smith, New, improved version of the Generic Mapping Tools released, EOS. Trans. AGU, 79, 579, 1998.

Yamazaki, T. and Y. Okamura, Subducting seamounts and deformation of overriding forearc wedges around Japan, Tectonophysics, 160, 207-229, 1989.

A. Nishizawa (e-mail: azusa@jodc.go.jp), K. Kaneda, N. Watanabe, and M. Oikawa 